CYSTIC FIBROSIS

\title{
Role of magnesium in the failure of rhDNase therapy in patients with cystic fibrosis
}

\author{
N N Sanders, H Franckx, K De Boeck, J Haustraete, S C De Smedt, J Demeester
}

Thorax 2006;61:962-968. doi: 10.1136/thx.2006.060814

See end of article for authors' affiliations

.....................

Correspondence to:

N N Sanders, PhD,

Laboratory of General

Biochemistry and Physical

Pharmacy, Faculty of

Pharmacy, Ghent

University, Harelbekestraat

72, 9000 Ghent, Belgium;

niek.sanders@ugent.be

Received 16 February 2006

Accepted 30 June 2006
Background: In the management of cystic fibrosis (CF), rhDNase-l inhalation is widely used to facilitate the removal of the highly viscous and elastic mucus (often called sputum) from the lungs. However, an important group of CF patients does not benefit from rhDNase-I treatment. A study was undertaken to elucidate the reason for the failure of rhDNase-I in these patients and to evaluate strategies to overcome this.

Methods: The biochemical properties, physical properties, and degradation by rhDNase-I of sputum obtained from clinical responders and non-responders to rhDNase-I were compared, and the ability of magnesium to reactivate rhDNase-I in DNA solutions and in sputum was investigated. The effect of oral magnesium supplements on magnesium levels in the sputum of patients with CF was also examined.

Results: Sputum from clinical responders was extensively degraded in vitro on incubation with rhDNase-I, while sputum from clinical non-responders was not degraded: the median decrease in sputum elasticity in the two groups was $32 \%$ and $5 \%$, respectively. Sputum from clinical responders contained significantly higher concentrations of magnesium than sputum from non-responders ( $2.0 \mathrm{mM} v 1.3 \mathrm{mM} ; \mathrm{p}=0.020)$. Sputum that could not be degraded by rhDNase-I became degradable after preincubation with magnesium. The effect of magnesium on rhDNase-I activity was mediated through actin. Oral intake of magnesium enhanced the magnesium concentration in the sputum of CF patients.

Conclusion: Increasing the magnesium concentration in sputum by, for example, oral magnesium supplements may be a promising new strategy to overcome the failure of rhDNase-l in patients with CF.
$\mathrm{C}$ ystic fibrosis (CF) is characterised by the presence of highly viscous and elastic mucus in the lungs. ${ }^{1}$ The origin of this pathological mucus has been associated with a mutation in the cystic fibrosis transmembrane conductance regulator (CFTR) gene. ${ }^{2}$ This gene codes for a protein which functions as a chloride channel in the apical membrane of epithelial cells. ${ }^{3}$ In the lung a defective CFTR protein is thought to lead to decreased chloride flux from the epithelial cells into the respiratory mucus and increased sodium flux from the mucus into the cells. These disturbances in ion fluxes result in water absorption from the mucus into the cells, which enhances the mucus viscosity and elasticity and consequently impedes the clearance of the mucus where inhaled pathogens are captured. ${ }^{3-5}$ As a result of the impaired clearance of inhaled pathogens, chronic colonisation of the lungs with pathogens is very common in patients with CF. In addition, it has been hypothesised that the gene defect in CF may lead to altered mucins and cellular glycoprotein receptors which bind bacteria more tightly. ${ }^{6}$ No matter which hypothesis holds true, the mutated CFTR gene results in chronic bacterial infection of the airways which evokes migration of serum proteins and neutrophils into the mucus. ${ }^{8}$ However, these neutrophils-together with the pathogens and epithelial cells-also die and their nuclear DNA and actin is released into the mucus. These biopolymers further enhance the viscidity of the mucus and decrease its clearance. ${ }^{9-11}$ Highly viscous and elastic respiratory mucus also causes suffering and even morbidity in other diseases such as sinusitis, chronic bronchitis, and lung atelectasis. ${ }^{12}{ }^{13}$

To facilitate the removal of tenacious lung secretions, drugs that decrease mucus viscosity and elasticity are often used. In different lung diseases, and especially in $\mathrm{CF}$, recombinant human DNase-I (rhDNase-I; E.C.3.1.21.1) is routinely inhaled. ${ }^{14}$ This enzyme decreases the viscosity and elasticity of infected mucus by hydrolysing the phosphodiester bonds of the DNA chains, resulting in shorter oligonucleotides. Although clinical trials have shown that rhDNase-I significantly improves lung function in patients with CF, it does not mean that all patients benefit from this treatment. ${ }^{15-17}$ Indeed, different studies have shown a wide variation in the clinical response to rhDNase-I with about $30 \%$ of patients - the so-called non-responders-not benefiting from it. ${ }^{18-20}$ The reason for the failure of rhDNase-I in these patients is not understood. This study was therefore undertaken to elucidate the reason for the failure of rhDNase-I in certain CF patients and to evaluate strategies to overcome this.

Lung function, sex, and age of clinical responders and nonresponders to rhDNase-I were compared and the concentration of the following biochemical parameters in their sputum samples was determined:

- Actin, which has been reported to be an inhibitor of DNase-I. ${ }^{21}$

- Calcium and magnesium ions as they are required, respectively, for the stability and activity of rhDNase-I. ${ }^{22}{ }^{23}$.

- DNA and mucin content of the sputum because the effect of rhDNase-I on sputum with low amounts of DNA or high amounts of mucin relative to the amount of DNA may be limited.

- The most abundant cations (sodium, potassium, calcium, magnesium) and anions (chloride, bicarbonate, inorganic phosphate) found in extracellular fluids because it has been reported that the activity of DNase-I decreases as the ion concentration increases. ${ }^{24}$

Abbreviations: $\mathrm{CF}$, cystic fibrosis; $\mathrm{FEV}_{1}$, forced expiratory volume in 1 second; FVC, forced vital capacity; G', elasticity; G", viscosity 
- Viscosity and elasticity of the sputum as it may be more difficult for rhDNase-I to penetrate into more tenacious sputum..$^{25}$

\section{METHODS \\ Subjects}

This study involved three cohorts of CF patients recruited consecutively. Patients were excluded from the study if they had acute exacerbations, could not expectorate sputum, expectorated sputum that was extensively contaminated with saliva, or if they did not give consent. Patients who needed major changes in their treatment during the study were also excluded.

The first cohort consisted of 22 patients who passed the exclusion criteria and attended the CF Centre in De Haan (Belgium) at the time of the study. The patients who were on rhDNase-I had started the treatment at least 1 year before the start of the study. The clinical and in vitro response to rhDNase-I and the biochemical composition of the sputum of these patients was determined. The second cohort consisted of 11 randomly selected patients whose clinical response to rhDNase-I was not examined. Sputum collected from these patients was used to evaluate whether addition of magnesium to their sputum could restore or enhance the capacity of rhDNase-I to degrade CF sputum. In a third cohort of 23 patients the effect of oral magnesium supplements on the magnesium levels in sputum and serum was determined. Patients in the second and third cohorts were patients that passed the exclusion criteria and attended the University Hospital Gasthuisberg (Leuven, Belgium) at the time of the study.

The study was approved by the local institutional ethical review board and all patients gave their consent.

\section{Collection of sputum}

Sputum was collected by expectoration after physiotherapy manoeuvres (percussion, breathing exercises). In this study a "sputum sample" is defined as the sputum collected from one patient during a 30 minute period of physiotherapy. After collection the sputum samples were divided into small fractions and immediately analysed. If necessary, small remnants of saliva were removed from the sputum by mild centrifugation. It was ethically difficult to stop patients receiving rhDNase-I, so sputum samples were collected in the morning just before treatment with rhDNase-I aerosol or other mucolytic drugs. Sinicropi $e t a l^{26}$ reported that sputum from patients given $2.5 \mathrm{mg}$ rhDNase-I twice a day contained no therapeutic levels of rhDNase-I 2 hours after treatment and no detectable levels were found before the next treatment. Sputum samples collected in this study were not therefore expected to contain rhDNase-I.

\section{In vitro/in vivo correlation of efficacy of rhDNase-I}

The clinical response to rhDNase-I was determined in the first cohort of patients. Clinical responders and nonresponders were defined as patients who showed a mean change in forced expiratory volume in 1 second $\left(\mathrm{FEV}_{1}\right)$ of $>5 \%$ or $<5 \%$, respectively, in the 3 months after starting rhDNase-I. During this period no major changes in treatment occurred. To calculate the change in lung function in each patient, at least two $\mathrm{FEV}_{1}$ and forced vital capacity (FVC) values before and after rhDNase-I treatment were taken. A time frame of 3 months was chosen as it had been shown by Davies et $a^{27}$ that the response to daily rhDNase-I at 3 months is highly predictive of the long term benefit. $\mathrm{FEV}_{1}$ is a measure of airflow obstruction and is the best discriminator of response to rhDNase-I. ${ }^{18}$ The sputum samples from this group of patients (nine clinical non-responders and 13 clinical responders to rhDNase-I; none had to be excluded during the study) were subsequently used to measure the in vitro effect of rhDNase-I (Pulmozyme; Roche, Belgium) and the concentration of different components of the sputum. As these experiments are time consuming, a maximum of two sputum samples could be processed each day so patients in this part of the study were selected consecutively. Laboratory staff were masked to the response status of the patients.

\section{Viscosity and elasticity measurements}

A controlled stress rotation rheometer (AR1000, TAInstruments, Brussels, Belgium) was used to determine the elastic $\left(G^{\prime}\right)$ and viscous modulus $\left(G^{\prime \prime}\right)$ of the sputum samples. ${ }^{28}$ These moduli characterise, respectively, the elasticity and viscosity of the sputum. Dynamic oscillatory measurements were performed using a cone plate set-up. The angle between the cone $(4 \mathrm{~cm}$ diameter $)$ and the plate was $2^{\circ}$ and the sample volume required was $1.0 \mathrm{ml}$. To avoid disruption of the weak biopolymer network in the sputum due to the oscillation forces, the measurements were performed in the linear viscoelastic region at a constant frequency of $1 \mathrm{~Hz}$ with a stress ranging from 0.01 to $0.10 \mathrm{~Pa}$. Furthermore, to slow down the enzymatic degradation (by proteases) and dehydration of the sputum, the experiments were carried out at $20^{\circ} \mathrm{C}$. A solvent trap was also used to prevent dehydration of the sample. The experiments were performed on at least two sputum fractions taken from each sputum sample and the data were averaged.

\section{Determination of the in vitro effect of rhDNase-I}

The degradation of CF sputum by rhDNase-I was characterised by measuring the change in $G^{\prime}$ and $G^{\prime \prime}$ of the sputum on incubation with an rhDNase-I solution or a control solution. A $1.0 \mathrm{ml}$ sputum fraction was taken from each sputum sample and $G^{\prime}$ and $G^{\prime \prime}$ were measured at $20^{\circ} \mathrm{C}$. Subsequently, $86 \mu \mathrm{l}$ rhDNase-I solution (rhDNase-I diluted in solution A: $150 \mathrm{mM} \mathrm{NaCl}+1.35 \mathrm{mM} \mathrm{CaCl}_{2}$ ) was mixed with the sputum fraction. The final rhDNase-I concentration in the sputum was $10 \mu \mathrm{g} / \mathrm{ml}$, which approaches the rhDNaseI concentration measured in the sputum of CF patients after inhalation of rhDNase-I. ${ }^{26}$ After 20 minutes incubation at $20^{\circ} \mathrm{C}, \mathrm{G}^{\prime}$ and $\mathrm{G}^{\prime \prime}$ of the sputum were again determined. As a control, $86 \mu \mathrm{l}$ of solution A (without rhDNase-I) was added to another $1.0 \mathrm{ml}$ sputum fraction taken from the same sputum sample. Again, $G^{\prime}$ and $G^{\prime \prime}$ were measured before and 20 minutes after adding solution A to the sputum fraction. Finally, the in vitro effect of rhDNase-I on a sputum sample was calculated by subtracting the percentage decrease in $G^{\prime}$ and $G^{\prime \prime}$ caused by solution A (control) from the percentage decrease in $G^{\prime}$ and $G^{\prime \prime}$ caused by the rhDNase-I containing solution. Experiments were performed on at least two sputum fractions taken from each sputum sample and the data were averaged.

\section{Biochemical analysis of CF sputum}

Determination of the actin concentration in sputum was based on the specific binding of rhodamine-labelled phalloidin (Sigma, Bornem, Belgium) with filamentous actin (Factin). ${ }^{9}$ Briefly, sputum samples were incubated for 30 minutes at $37^{\circ} \mathrm{C}$ with potassium, magnesium, calcium, and ATP at a final concentration of $150 \mathrm{mM}, 2 \mathrm{mM}, 0.1 \mathrm{mM}$, and $0.5 \mathrm{mM}$, respectively. At these ion concentrations, globular actin (G-actin) maximally polymerises into F-actin. The sputum was subsequently incubated with rhodaminelabelled phalloidin $(1.4 \mu \mathrm{M})$ for 1 hour on ice in the dark. The sputum was then washed three times and the bound rhodamine-phalloidin was extracted overnight at $4{ }^{\circ} \mathrm{C}$ with methanol. Fluorescence was measured at $580 \mathrm{~nm}$ upon 
excitation at $550 \mathrm{~nm}$. The background fluorescence of the sputum, obtained by prior incubation of the sputum with unlabeled phalloidin $(14 \mu \mathrm{M})$, was subtracted from the measured fluorescence. The calcium, chloride, sodium, DNA, and mucin concentrations in the sputum samples were measured using previously reported protocols. ${ }^{29}$ The osmolality of the sputum was determined using a cryoscope (model 3C2, Advanced Instruments, Norwood, Massachusetts, USA), while the potassium concentration was measured using an ion selective electrode. The bicarbonate, inorganic phosphate, and magnesium concentrations were measured using standard procedures. $^{30}$ For all the assays except for the determination of DNA and mucin, the sputum samples were diluted twofold with a dithiothreitol (DTT) solution $(6.5 \mathrm{mM}$ DTT in $100 \mathrm{mM} \mathrm{NaH} \mathrm{PO}_{4}$ at $\mathrm{pH}$ 7.4) and analysed using an autoanalyser (Hitachi 747, Hitachi, Tokyo, Japan). All assays were performed on three sputum fractions taken from each sputum sample and the data were averaged.

\section{Effect of magnesium on the in vitro degradation of CF sputum by rhDNase-I}

In this part of the work we used sputum samples collected from 11 randomly selected CF patients (cohort 2). Degradation of the CF sputum by rhDNase-I was determined as described above, and the effect of magnesium on the capacity of rhDNase-I to degrade the sputum was then studied as follows. From each sputum sample, $1.0 \mathrm{ml}$ sputum was used to determine $G^{\prime}$ and $G^{\prime \prime} .45 \mu$ of a magnesium chloride solution (solution B: $115 \mathrm{mM} \mathrm{MgCl}_{2}, 24 \mathrm{mM}$ ATP, $85 \mathrm{mM} \mathrm{NaCl}$ ) was then gently added to the sputum and the mixture was incubated for 30 minutes at $37^{\circ} \mathrm{C}$ to allow polymerisation of G-actin. $45 \mu \mathrm{l}$ rhDNase-I solution was then added to give a final rhDNase-I concentration of $10 \mu \mathrm{g} / \mathrm{ml}$ sputum. After incubation for 20 minutes at $20^{\circ} \mathrm{C}$, the $\mathrm{G}^{\prime}$ and $G^{\prime \prime}$ of the sputum fraction were determined again. In the control experiment the same procedure was followed, but $45 \mu \mathrm{l}$ rhDNase-I solution was replaced by $45 \mu \mathrm{l}$ solution A.

\section{Viscosity measurements on DNA and DNA/actin}

For these experiments, DNA from salmon testes (Sigma) and actin extracted from rabbit skeletal muscles according to Spudich et al was used. ${ }^{31}$ DNA $(2.6 \mathrm{mg} / \mathrm{ml})$ and DNA/actin (2.6 $\mathrm{mg} \mathrm{DNA} / \mathrm{ml}$ and $0.08 \mathrm{mg}$ actin $/ \mathrm{ml}$ ) solutions were prepared in $5 \mathrm{mM}$ Tris buffer containing $70 \mathrm{mM} \mathrm{NaCl}$, $3 \mathrm{mM} \mathrm{CaCl} 2 \cdot 2 \mathrm{H}_{2} \mathrm{O}, 0.5 \mathrm{mM} \mathrm{ATP}, 0.2 \mathrm{mM} \mathrm{DTT}, 0.01 \% \mathrm{NaN}_{3}$, and increasing concentrations of magnesium chloride and/or potassium phosphate. The mean (SE) pH of the solutions was 7.4 (0.06). After preparation the solutions were incubated for 30 minutes at $37^{\circ} \mathrm{C}$. A calibrated capillary microviscosimeter (No. 53710, Schott Geräte, Hofheim, Germany) was used to determine the effect of rhDNase-I $(10 \mu \mathrm{g} / \mathrm{ml})$ on the kinematic viscosity of the DNA and DNA/actin solutions. The capillary microviscosimeter was placed in a water bath at a mean (SE) temperature of $20.00(0.05){ }^{\circ} \mathrm{C}$ and the outflow times were determined automatically (Lauda, Köningshofen, Germany). The percentage decrease in viscosity due to rhDNase-I was calculated from the viscosity of the solution in the absence of rhDNase-I and the viscosity of the solution after incubation for 20 minutes with rhDNase-I.

\section{Effect of oral magnesium supplements on magnesium concentration in sputum and serum}

The effect of oral magnesium gluconate (162 mg elemental magnesium three times a day for 14 days) on the magnesium concentration in sputum and serum was evaluated in $12 \mathrm{CF}$ patients ("magnesium group") of cohort 3. Eleven other CF patients in this cohort who did not receive magnesium served as the control group. The patients in the magnesium and control groups were a random subset of CF patients who passed the above mentioned exclusion criteria. The clinical response of these patients to rhDNase-I was not examined. To prevent saturation of the uptake of magnesium in the intestine, we divided the total maximal daily dose of magnesium into three single doses..$^{32}$ An organic rather than an inorganic magnesium salt was used as the former has a higher absorption. ${ }^{33}$ At the start and end of the trial we collected one sputum sample and one blood sample from each patient. The magnesium concentration was determined in three sputum fractions taken from each sputum sample and the data were averaged. The blood samples were not divided into fractions before analysis.

\section{Statistical analysis}

The data in this study often showed either a non-normal distribution or an unequal variance, so the non-parametric Mann-Whitney test or the Kruskal-Wallis test was used for analysis. All results are presented as median (interquartile range, IQR) unless otherwise stated. $p$ values of $<0.05$ were considered significant. SPSS version 12.0 was used for all analyses (SPSS Inc, Chicago, IL, USA).

\section{RESULTS}

\section{In vitro/in vivo correlation of efficacy of rhDNase-I}

The in vitro effect of rhDNase-I on $G^{\prime}$ and $G^{\prime \prime}$ of sputum obtained from 13 clinical responders and nine clinical nonresponders was measured. The clinical characteristics of the patients included in this experiment are summarised in table 1. There was no significant difference in the mean age and lung function of patients in the two groups; responders had a significantly greater improvement in lung function than non-responders.

The $G^{\prime}$ and $G^{\prime \prime}$ of the sputum samples before degradation by rhDNase-I in the clinical responder group were not significantly different from the values of the clinical nonresponder group (median (IQR) $\mathrm{G}^{\prime}=5.3(3.2-14.0)$ Pa $v 6.0$ (3.1-9.5) Pa, p=0.789; $\mathrm{G}^{\prime \prime}=2.1 \quad(1.3-3.8)$ Pa $v 1.9$ (1.2-

Table 1 Characteristics of clinical responders and non-responders and change in FEV and FVC after rhDNase-I treatment

\begin{tabular}{llll}
\hline & $\begin{array}{l}\text { Responders } \\
(\mathbf{n}=13)\end{array}$ & $\begin{array}{l}\text { Non-responders } \\
(\mathbf{n}=9)\end{array}$ & p values* \\
\hline Age (years) & $20(16-23)$ & $22(21-29)$ & 0.081 \\
Sex (F/M) & $6 / 7$ & $6 / 3$ & 0.425 \\
FEV $1 \%$ predicted) $\dagger$ & $59(57-68)$ & $52(35-70)$ & 0.425 \\
FVC (\% predicted) $\dagger$ & $83(62-91)$ & $76(44-82)$ & 0.020 \\
Change in FEV $1 \%)$ & $10(8-12)$ & $-3(-4$ to -1$)$ & 0.019 \\
Change in FVC (\%) & $7(6-10)$ & $-2(-3$ to -2$)$ & \\
\hline
\end{tabular}

$\mathrm{FEV}_{1}$, forced expiratory volume in 1 second; FVC, forced vital capacity Values shown as median (interquartile range). *Two tailed Mann-Whitney test. tBefore treatment with rhDNase-I. 
Table 2 Biochemical composition of sputum obtained from clinical responders and nonresponders

\begin{tabular}{llll}
\hline & $\begin{array}{l}\text { Responders } \\
(\mathbf{n}=13)\end{array}$ & $\begin{array}{l}\text { Non-responders } \\
(\mathbf{n}=9)\end{array}$ & p value* $^{*}$ \\
\hline Calcium (mM) & $3.0(2.4-3.6)$ & $3.0(2.6-3.4)$ & 0.815 \\
Chloride (mM) & $75(67-87)$ & $75(70-96)$ & 0.920 \\
Bicarbonate (mM) & $12.5(5.7-18.5)$ & $8.9(5.1-11.9)$ & 0.133 \\
Inorganic phosphate $(\mathrm{mM})$ & $14.2(7.6-24.4)$ & $12.0(7.6-12.6)$ & 0.135 \\
Magnesium (mM) & $2.0(1.5-2.6)$ & $1.3(1.1-1.5)$ & 0.020 \\
Potassium (mM) & $21.9(19.4-23.7)$ & $18.1(16.0-19.3)$ & 0.016 \\
Sodium (mM) & $85(80-104)$ & $92(81-106)$ & 0.894 \\
Osmolality (mosmol/kg) & $258(235-292)$ & $228(222-250)$ & 0.057 \\
DNA (mg/ml) & $3.2(1.8-4.1)$ & $2.3(1.6-3.5)$ & 0.367 \\
Mucin (mg/ml) & $18.9(12.3-21.0)$ & $10.7(10.2-23.7)$ & 0.439 \\
Total (G+F) actin (mg/ml) & $0.06(0.03-0.09)$ & $0.07(0.04-0.10)$ & 0.736 \\
\hline Values shown as median (interquartile range). & & \\
*Two tailed Mann-Whitney test. & & & \\
\hline
\end{tabular}

2.6) $\mathrm{Pa}, \mathrm{p}=0.483$, two tailed Mann-Whitney test). In agreement with the clinical response, the sputum samples of clinical responders were extensively degraded in vitro on incubation with rhDNase-I with a median (IQR) decrease in $\mathrm{G}^{\prime}$ and $\mathrm{G}^{\prime \prime}$ of $32(23-38) \%$ and $17(12-32) \%$, respectively. Sputum from clinical non-responders was barely liquefied (median (IQR) decrease in $\mathrm{G}^{\prime}$ and $\mathrm{G}^{\prime \prime}$ of 5 (1-9)\% and 5 (-6$14) \%$, respectively); these decreases were significantly lower than those seen in sputum from clinical responders ( $p=0.001$ and $p=0.007$ for $G^{\prime}$ and $G^{\prime \prime}$, respectively; two tailed Mann-Whitney test).

\section{Magnesium and potassium concentrations in sputum of clinical responders}

A comparison of the concentrations of bicarbonate, calcium, chloride, inorganic phosphate, magnesium, potassium, sodium, actin (globular and filamentous), DNA, mucin, and the osmolality in sputum of clinical responders and nonresponders revealed that only the magnesium and potassium concentrations differed significantly between the two groups (table 2). Sputum from clinical responders had a significantly higher potassium concentration (median (IQR) 21.9 (19.423.7) $\mathrm{mM} v 18.1$ (16.0-19.3) $\mathrm{mM} ; \mathrm{p}=0.016$, two tailed Mann-Whitney test) and magnesium concentration (2.0 (1.5-2.6) mM $v 1.3(1.1-1.5) \mathrm{mM} ; \mathrm{p}=0.020$, two tailed Mann-Whitney test) than sputum from clinical non-responders. There was no significant correlation between the magnesium and potassium concentrations in each group as shown by the Spearman correlation test (correlation

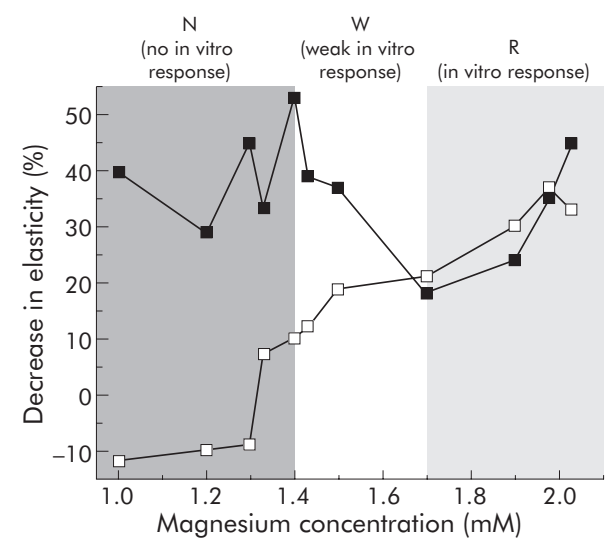

Figure 1 In vitro effect of rhDNase-I on the elasticity of CF sputum before (open squares) and after (closed squares) adding magnesium to the sputum samples $(n=1)$. The $x$ axis shows the initial magnesium concentration in the sputum before adding magnesium. coefficients $0.302(p=0.468)$ and $0.058(p=0.913)$ for clinical responders and non-responders, respectively). This indicates that the concentrations of magnesium and potassium in sputum from patients with CF vary independently of each other.

\section{Effect of magnesium on rhDNase-I activity}

To investigate the effect of magnesium on the activity of rhDNase-I in CF sputum, two sets of experiments were performed using sputum samples from a new cohort of 11 randomly selected CF patients. In the first set of experiments we again measured the decrease in $G^{\prime}$ and $G^{\prime \prime}$ of these new samples after incubation with rhDNase-I ( $10 \mu \mathrm{g} / \mathrm{ml}, 20 \mathrm{~min}$ utes, $20^{\circ} \mathrm{C}$ ). The effect of rhDNase-I varied considerably from sample to sample but, as shown in fig 1 , there was a significant positive correlation between the magnesium concentration and the decrease in $G^{\prime}$ (and $G^{\prime \prime}$ ) of the sputum upon treatment with rhDNase-I (Spearman correlation coefficients $0.99(\mathrm{p}<0.001)$ and $0.96(\mathrm{p}<0.001)$ for $\mathrm{G}^{\prime}$ and $\mathrm{G}^{\prime \prime}$, respectively). Three groups could be distinguished (fig l): (1) samples with a magnesium concentration $>1.7 \mathrm{mM}$ which were strongly liquefied by rhDNase-I (zone R, in vitro response); (2) samples with a magnesium concentration between $1.4 \mathrm{mM}$ and $1.7 \mathrm{mM}$ which were weakly degraded by rhDNase-I (zone W, weak in vitro response); and (3) samples with a magnesium concentration $<1.4 \mathrm{mM}$ which

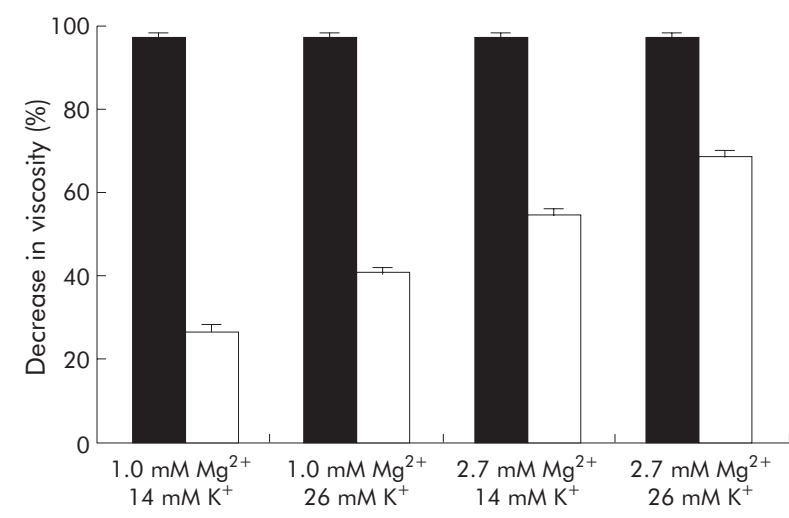

Figure 2 Effect of magnesium $\left(\mathrm{Mg}^{2+}\right)$ and potassium $\left(\mathrm{K}^{+}\right)$on the activity of rhDNase-l in DNA (black bars) and DNA/actin (white bars) solutions ( $n=4$, error bars represent the standard error of the mean). A high decrease in viscosity of the solution indicates high rhDNase-l activity. The magnesium and potassium concentrations on the $x$ axis represent concentrations found in sputum samples from emphatic clinical responders $\left(2.7 \mathrm{mM} \mathrm{Mg}^{2+}\right.$ and $\left.26 \mathrm{mM} \mathrm{K}^{+}\right)$and non-responders $\left(1.0 \mathrm{mM} \mathrm{Mg}^{2+}\right.$ and $\left.14 \mathrm{mM} \mathrm{K}^{+}\right)$. 


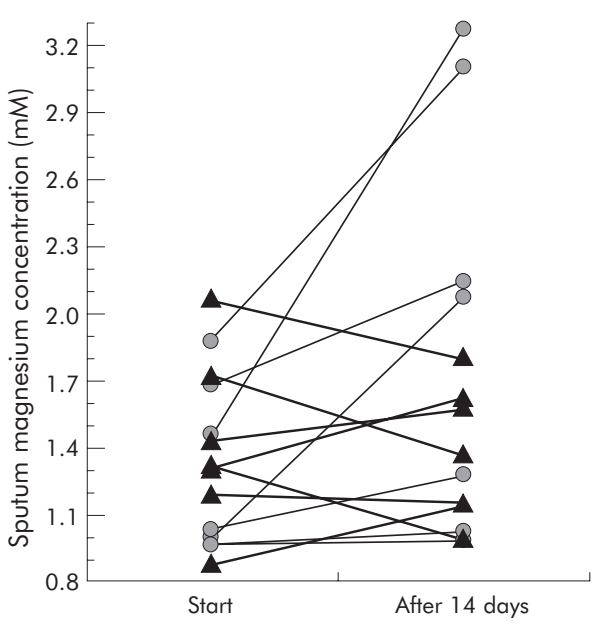

Figure 3 Effect of oral magnesium supplements on the concentration of magnesium in sputum of CF patients. The connected data points in the graph represent the mean ( $n=3$, SEM is smaller than the dot) magnesium concentration in a sputum sample of one patient at the start or at the end of the trial (after 14 days). Patients in the magnesium group (circles) received $162 \mathrm{mg}$ magnesium three times daily for 14 days while patients in the control group (triangles) received no magnesium.

were not degraded by rhDNase-I (zone $\mathrm{N}$, no in vitro response). In a second series of experiments we added magnesium chloride to the sputum samples from zones $\mathrm{N}, \mathrm{W}$ and $\mathrm{R}$ (final magnesium concentration $>5 \mathrm{mM}$ ). As shown in fig 1, this dramatically improved the capacity of rhDNase-I to degrade the samples in zone $\mathrm{N}$ and also improved the degradation by rhDNase-I of sputum samples from zone W, but did not further enhance the effect of rhDNase-I on sputum samples from zone $\mathrm{R}$.

\section{Effect of actin on rhDNase-I activity at low magnesium levels}

Figure 2 shows that, in DNA solutions $(2.6 \mathrm{mg} / \mathrm{ml}$, a concentration typically found in the CF sputum) without actin, the rhDNase-I activity was independent of the magnesium or potassium concentration. However, adding actin $(0.08 \mathrm{mg} / \mathrm{ml}$, a concentration typically found in the CF sputum) to the DNA solutions drastically reduced the ability of rhDNase-I to degrade DNA when magnesium and potassium concentrations representative of emphatic nonresponders (1.0 $\mathrm{mM}$ and $14 \mathrm{mM}$, respectively) were used. When the potassium concentration in the DNA/actin solutions was enhanced to the concentration found in emphatic clinical responders $(26 \mathrm{mM})$, a modest but significant increase in rhDNase-I activity was observed. However, the rhDNase-I activity doubled when the magnesium concentration was increased to the concentration found in emphatic clinical responders $(2.7 \mathrm{mM}) \quad(\mathrm{p}=0.003, \quad$ Kruskal-Wallis test).

\section{Effect of oral magnesium supplements on magnesium concentration in sputum}

The above findings suggest that increasing the magnesium concentration in the sputum of non-responders may overcome the failure of rhDNase-I, so the effect of oral magnesium (162 mg three times daily for 14 days) on the sputum magnesium concentration of $12 \mathrm{CF}$ patients ("magnesium group:) was evaluated. Eleven CF patients who did not receive magnesium served as the "control group". However, either no sputum sample or a sputum sample that was extensively contaminated with saliva was obtained from nine patients (five in the control and four in the magnesium group), so these nine patients were excluded from the study. Figure 3 shows the mean magnesium concentrations in the sputum of both groups at the start of the trial and 14 days later. The initial magnesium concentration did not differ significantly between the control and magnesium groups (median (IQR) $1.3(1.2-1.7) \mathrm{mM} \quad v \quad 1.1 \quad(1.0-1.7) \mathrm{mM}$, $\mathrm{p}=0.565$, two tailed Mann-Whitney test). Five of the seven patients in the magnesium group showed clear enhancement of the magnesium concentration in their sputum samples. Pronounced gastrointestinal problems may, at least for one of the patients in this group, explain the absence of a clear increase in the sputum magnesium concentration after 14 days of oral magnesium supplementation. Nevertheless, there was a significant increase in the sputum magnesium concentration after 14 days in patients in the magnesium group compared with the control group (median (IQR) increase $27(5-108) \% v-3(-21$ to -23$) \%$; $p=0.041$, two tailed Mann-Whitney test). Before oral supplementation the median (IQR) serum magnesium concentration in the control and magnesium groups was $0.78(0.73-0.82) \mathrm{mM}$ and 0.77 (0.63-0.91) mM, respectively ( $p=0.902$; two tailed MannWhitney test) and did not increase significantly after supplementation (median (IQR) change $5(-7$ to -19$) \%$ in the magnesium group and $7(-13$ to -27$) \%$ in the control group; $\mathrm{p}=0.943$, two tailed Mann-Whitney test).

\section{DISCUSSION}

It is well known that an important group of patients with CF does not benefit from rhDNase-I treatment. ${ }^{18-20}$ Our data show that sputum obtained from such clinical non-responders could also not be degraded in vitro with rhDNase-I, while sputum from clinical responders was extensively degraded by rhDNase-I. More importantly, biochemical analysis revealed that clinical responders produced sputum that contained significantly higher concentrations of potassium (and especially magnesium) than sputum from clinical non-responders. Magnesium serves as a cofactor in the enzymatic degradation of DNA by rhDNase- $\mathrm{I}^{34}$ so, to obtain

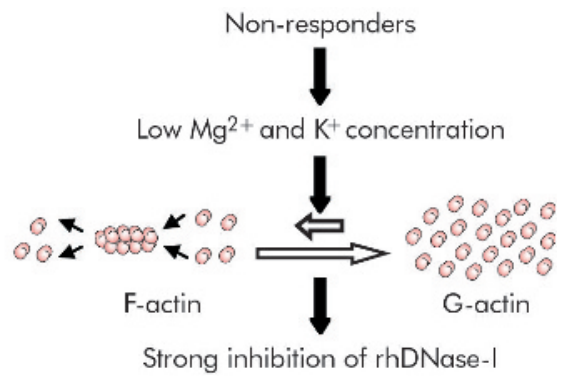

Figure 4 Postulated mechanism by which magnesium and potassium control the activity of rhDNase-l in sputum from patients with CF. The lower magnesium and potassium concentrations in CF sputum samples from clinical non-responders result in a higher concentration of G-actin and thus lower rhDNase-I activity, and vice versa. 
optimal rhDNase-I activity, a minimum concentration of magnesium is required.

We found that the differences in the magnesium (and potassium) concentrations in sputum from clinical responders and non-responders did not directly affect rhDNase-I activity. However, these ions indirectly triggered the activity of rhDNase-I in CF sputum by controlling the polymerisation of actin. Indeed, it has been reported that G-actin inhibits DNase-I and that both magnesium and potassium promote the polymerisation of G-actin into F-actin which does not inhibit DNase-I. ${ }^{21}{ }^{35}$ Our data indicate that the differences in potassium (and especially magnesium) concentrations between the two groups (magnesium: $2.0 \mathrm{mM} v 1.3 \mathrm{mM}$; potassium: $21.9 \mathrm{mM} \vee 18.1 \mathrm{mM}$ ) may be relevant in influencing the polymerisation state of actin. This is in agreement with the observation that polymerisation of actin starts from a concentration of about $0.4 \mathrm{mM}$ magnesium or $10 \mathrm{mM}$ potassium and reaches its maximum at a concentration of about $2.0 \mathrm{mM}$ magnesium or $50 \mathrm{mM}$ potassium. ${ }^{35}{ }^{36}$ Since responders and non-responders have comparable actin concentrations (table 2), we postulate that the magnesium and potassium concentrations in CF sputum control rhDNase-I activity by regulating the degree of polymerisation of actin (fig 4).

We further confirmed this hypothesis in two sets of experiments using sputum samples from a new cohort of 11 CF patients. In the first set of experiments we showed that the ability of rhDNase-I to degrade the sputum was dictated by the sputum concentration of magnesium. We also showed that addition of magnesium to sputum samples that were not degradable by rhDNase-I dramatically improved the capacity of rhDNase-I to degrade these samples. These results are in line with our hypothesis that the higher magnesium concentrations in sputum from clinical responders prevent the inhibition of rhDNase-I by G-actin. In the experiments shown in fig 1 we only considered the addition of magnesium (and not potassium) because (1) magnesium inhalation has already been used by asthmatic patients without major side effects, ${ }^{37}$ (2) administration of potassium to (the lungs of) CF patients may be more dangerous, and (3) the difference in the magnesium concentration between sputum from clinical responders and non-responders is much more pronounced than the difference in the potassium concentration.

Inhalation of a solution of magnesium salts would be the most direct way to enhance the magnesium concentration in the sputum of patients with CF. However, as inhalation is time consuming, we first decided to evaluate whether oral intake of magnesium could enhance the magnesium concentration in the sputum. The fact that magnesium levels in the sputum of four of seven patients with CF rose above $1.7 \mathrm{mM}$ (fig 3) is promising for further clinical application. Indeed, our data show that sputum containing magnesium in concentrations above $1.7 \mathrm{mM}$ is, at least in vitro, efficiently degraded by rhDNase-I.

The fact that the serum levels of magnesium did not increase after oral magnesium supplementation was not surprising. It is known that serum magnesium levels are kept in a narrow range $(0.7-1.1 \mathrm{mM}) .^{38}$ In addition, magnesium deficiency can be present without low serum magnesium concentrations as more than $99 \%$ of the total body magnesium is stored in bone, intracellular compartments, and other body fluids. ${ }^{39}$ Therefore, as the patients in both groups had normal serum magnesium levels, an excess of magnesium in their serum after supplementation with magnesium is expected to fill up shortages in the extravascular stores or to be eliminated by the kidneys.

Other groups have attempted to overcome the inhibition of rhDNase-I by actin using actin binding proteins such as gelsolin, ${ }^{40}$ or by developing DNase-I variants that are resistant to G-actin inhibition. ${ }^{41}{ }^{42}$ However, these strategies are expensive and involve modified (non-human) proteins which can provoke major side effects. Our results suggest a possible new and easier way to overcome the inhibition of rhDNase-I in CF patients through the simple combination of rhDNase-I with magnesium.

Potassium, and especially magnesium, deficiency has been associated with airway hyperactivity and impairment of lung function. ${ }^{43}{ }^{44}$ Moreover, it has been shown that intravenous, nebuliser, or oral administration of magnesium salts to patients with asthma or other chronic lung diseases improves lung function and lessens disease severity.44 ${ }^{45}$ Whether magnesium as such also enhances lung function in patients with CF is not known.

Information on the ion composition of the sputum from patients with CF is limited and sometimes contradictory. Levy et $a{ }^{46}$ reported calcium, magnesium, sodium, potassium, and inorganic phosphate levels in CF sputum that were comparable to our data. Halmerbauer et $a l^{47}$ reported median concentrations of sodium, chloride, calcium, and magnesium in $\mathrm{CF}$ sputum of $135 \mathrm{mM}, 80 \mathrm{mM}, 0.7 \mathrm{mM}$ and $1.2 \mathrm{mM}$, respectively. They also found that sputum of patients with bronchial asthma contained significantly lower sodium, chloride, and calcium concentrations. The sodium, chloride, and potassium concentrations found in our study were also in agreement with the results of Kilbourn et $a l^{48}$ and Tomkiewicz et al. ${ }^{49}$ However, the former group reported calcium and magnesium concentrations that were much lower than ours. The DNA and mucin concentrations measured in the sputum of our patients were consistent with previously reported data, while the actin concentrations were slightly lower than those reported by Vasconcellos et al. ${ }^{29}$

Many factors may be responsible for the variability in magnesium and potassium concentrations in CF sputum. Firstly, in the early 1980s it was shown that sputum magnesium levels are increased in CF patients infected with mucoid Pseudomonas aeruginosa. ${ }^{48} 50$ Secondly, an insufficient intake may account for the lower magnesium and potassium concentrations in the sputum of non-responders. ${ }^{43}$ Thirdly, it is well known that gastrointestinal malabsorption, a common symptom in CF, may cause hypomagnesaemia and hypopotassaemia. ${ }^{51}$ Fourthly, certain antibiotics and chemotherapeutics are also known to induce hypomagnesaemia and hypopotassaemia. ${ }^{52}$ Muscle cramps and tetany due to magnesium deficiency, which was in most cases caused by prolonged use of aminoglycosides, has been described in CF patients. ${ }^{53} 54$ Supplementation of CF patients with magnesium may therefore not only favour the clinical response to rhDNase-I but also prevent diseases associated with magnesium deficiency.

The findings reported here show that the concentration of magnesium in the sputum of CF patients governs the in vitro and probably also the in vivo effect of rhDNase-I. Measuring the sputum concentration of magnesium in patients with CF may therefore be a rapid way of predicting a patient's response to rhDNase-I treatment. However, the lack of a clinical response to rhDNase-I may be a time dependent feature that only occurs spasmodically, although we recently found in an unpublished study that the magnesium concentrations in sputum from 15 patients did not fluctuate significantly over a period of several weeks. This may suggest that the response to rhDNase-I also does not fluctuate much during this period.

In conclusion, we have reported a mechanism that may explain the failure of rhDNase-I treatment in some patients with CF. We found that the magnesium concentration in sputum from clinical non-responders to rhDNase-I is significantly lower than in the sputum of clinical responders. 
The addition of magnesium to sputum samples that could not be degraded by rhDNase-I enabled them to be degraded by rhDNase-I. We have shown that the effect of magnesium on rhDNase-I activity is mediated through actin, and that oral intake of magnesium enhanced the magnesium concentration in the sputum of CF patients. The failure of rhDNase-I may therefore be overcome by combining rhDNase-I with oral magnesium supplements. We propose to perform further studies to confirm this and to elucidate why non-responders have lower magnesium levels in their sputum.

\section{ACKNOWLEDGEMENTS}

Niek Sanders is a postdoctoral fellow of FWO (Fund for Scientific Research-Flanders). The financial support of this institute is acknowledged. The authors are grateful to Professor J De Langhe (Ghent University) for the use of the Hitachi 747.

\section{Authors' affiliations}

N N Sanders, J Haustraete, S C De Smedt, J Demeester, Laboratory of General Biochemistry and Physical Pharmacy, Faculty of Pharmacy, Ghent University, Harelbekestraat 72, 9000 Ghent, Belgium H Franckx, Zeepreventorium, Koninklijke Baan 5, 8420 De Haan, Belgium

K De Boeck, Department of Paediatrics, University Hospital Gasthuisberg, Herestraat 49, 3000 Leuven, Belgium

This work was supported by grants from Ghent University, the Belgian Cystic Fibrosis Association, and the fund for scientific research-Flanders (grants G.0310.02 and G.0320.04). RhDNase-I (Pulmozyme ${ }^{\circledR}$ ) was a gift from $N$ V Roche SA, Brussels, Belgium.

Competing interests: none.

\section{REFERENCES}

1 Davis PB. Cystic fibrosis since 1938. Am J Respir Crit Care Med 2006; 173:475-82

2 Collins FS. Cystic fibrosis: molecular biology and therapeutic implications. Science 1992;256:774-9.

3 Sheppard DN, Welsh MJ. Structure and function of the CFTR chloride channel. Physiol Rev 1999;79:S23-45.

4 Mall $M$, Bleich $M$, Greger $\mathrm{R}$, et al. The amiloride-inhibitable $\mathrm{Na}^{+}$conductance is reduced by the cystic fibrosis transmembrane conductance regulator in normal but not in cystic fibrosis airways. J Clin Invest 1998;102:15-21.

5 Guggino WB. Cystic fibrosis salt/fluid controversy: in the thick of it. Nat Med 2001;7:888-9.

6 Imundo L, Barasch J, Prince A, et al. Cystic fibrosis epithelial cells have a receptor for pathogenic bacteria on their apical surface. Proc Natl Acad Sci USA 1995;92:3019-23.

7 Xia BY, Royall JA, Damera G, et al. Altered O-glycosylation and sulfation of airway mucins associated with cystic fibrosis. Glycobiology 2005;15:747-75.

8 Konstan MW, Berger M. Current understanding of the inflammatory process in cystic fibrosis: onset and etiology. Pediatr Pulmonol 1997;24:137-42.

9 Vasconcellos CA, Allen PG, Wohl ME, et al. Reduction in viscosity of cystic fibrosis sputum in vitro by gelsolin. Science 1994;263:969-71.

10 Zahm JM, Girod de Bentzmann S, Deneuville E, et al. Dose-dependent in vitro effect of recombinant human DNase on rheological and transport properties of cystic fibrosis respiratory mucus. Eur Respir J 1995;8:381-6.

11 Sheils CA, Kas J, Travassos W, et al. Actin filaments mediate DNA fiber formation in chronic inflammatory airway disease. Am J Pathol 1996; 148:919-27.

12 El-Hassan NO, Chess PR, Huysman MW, et al. Rescue use of DNase in critical lung atelectasis and mucus retention in premature neonates. Pediatrics 2001;108:468-70.

13 Yuta A, Baraniuk JN. Therapeutic approaches to mucus hypersecretion. Curr Allergy Asthma Res 2005;5:243-51.

14 Suri R. The use of human deoxyribonuclease (rhDNase) in the management of cystic fibrosis. Biodrugs 2005; 19:135-44.

15 Fuchs HJ, Borowitz DS, Christiansen DH, et al. Effect of aerosolized recombinant human DNase on exacerbations of respiratory symptoms and on pulmonary function in patients with cystic fibrosis. N Engl J Med 1994;331:637-42.

16 Shah PL, Scott SF, Geddes DM, et al. Two years' experience with recombinant human DNase I in the treatment of pulmonary disease in cystic fibrosis. Respir Med 1995;89:499-502.

17 Harms HK, Matouk E, Tournier G, et al. Multicenter, open-label study of recombinant human DNase in cystic fibrosis patients with moderate lung disease. Pediatr Pulmonol 1998;26:155-61.

18 Bollert FGE, Paton JY, Marshall TG, et al. Recombinant DNase in cystic fibrosis: a protocol for targeted introduction through n-of-1 trials. Eur Respir J 1999;13:107-13.
19 Christopher F, Chase D, Stein K, et al. rhDNase therapy for the treatment of cystic fibrosis patients with mild to moderate lung disease. J Clin Pharm Ther 1999;24:415-26.

20 Cobos N, Danes I, Gartner S, et al. DNase use in the daily care of cystic fibrosis: who benefits from it and to what extent? Results of a cohort study of 199 patients in 13 centres. Eur J Pediatr 2000;159:176-81.

21 Lazarides $E$, Lindberg $U$. Actin is the naturally occurring inhibitor of deoxyribonuclease I. Proc Natl Acad Sci USA 1974;71:4742-6.

22 Campbell VW, Jackson DA. The effect of divalent cations on the mode of action of DNase I. The initial reaction products produced from covalently closed circular DNA. J Biol Chem 1980;255:3726-35.

23 Chen B, Costantino HR, Liu J, et al. Influence of calcium ions on the structure and stability of recombinant human deoxyribonuclease $\mathrm{I}$ in the aqueous and lyophilized states. J Pharm Sci 1999;88:477-82.

24 Sorrentino S, Yakovlev GI, Libonati M. Dimerization of deoxyribonuclease I, lysozyme and papain: effects of ionic strength on enzymic activity. Eur J Biochem 1982; 124:183-9.

25 Larhed AW, Artursson P, Grasjo J, et al. Diffusion of drugs in native and purified gastrointestinal mucus. J Pharm Sci 1997:86:660-5.

26 Sinicropi MW, Prince WS, Lofgren JA, et al. Sputum pharmacodynamics and pharmacokinetics of recombinant DNase I in cystic fibrosis. Am J Respir Crit Care Med 1994;149:A671

27 Davies J, Trindade MT, Wallis C et al. Retrospective review of the effects of rhDNase in children with cystic fibrosis. Pediatr Pulmonol 1997:23:243-8.

28 Sanders NN, De Smedt SC, Van Rompaey E, et al. Cystic fibrosis sputum: a barrier to the transport of nanospheres. Am J Respir Crit Care Med 2000;162:1905-11.

29 Sanders NN, Van Rompaey E, De Smedt SC, et al. Structural alterations of gene complexes by cystic fibrosis sputum. Am J Respir Crit Care Med 2001; 164:486-93.

30 Tietz NW. Clinical guide to laboratory tests. Philadelphia, PA: WB Saunders Company, 1995, 110-11, 380-2, 1841.

31 Spudich JA, Watt S. The regulation of rabbit skeletal muscle contraction. J Biol Chem 1971;246:4866-71.

32 Classen HG, Classen UG, Grimm P, et al. Pharmacokinetics of magnesium salts. Meth Find Exp Clin Pharmacol 1992;14:261-8

33 Firoz M, Graber M. Bioavailability of US commercial magnesium preparations. Magnes Res $2001 ; 14: 257-62$.

34 Sanders NN, De Smedt SC, Demeester J. Acoxyribonucle I. In: Mcgrath BM, Walsh G, eds. Directory of therapeutic enzymes. Boca Raton, FL: Taylor \& Francis, 2006:97-116.

35 Maruyama K, Tsukagoshi K. Effects of $\mathrm{KCl}, \mathrm{MgCl}_{2}$, and $\mathrm{CaCl}_{2}$ concentrations on the monomer-polymer equilibrium of actin in the presence and absence of cytochalasin D. J Biochem 1984;96:605-11.

36 Shu WP, Wang D, Stracher A. Chemical evidence for the existence of activated G-actin. Biochem J 1992:283:567-73.

37 Hughes R, Goldkorn A, Masoli M, et al. Use of isotonic nebulised magnesium sulphate as an adjuvant to salbutamol in treatment of severe asthma in adults: randomised placebo-controlled trial. Lancet 2003;361:2114-7.

38 Konrad M, Schlingmann KP, Gudermann T. Insights into the molecular nature of magnesium homeostasis. Am J Physiol Renal Physiol 2004;286:F599-605.

39 Elin RJ. Magnesium: the fifth but forgotten electrolyte. Am J Clin Pathol 1994; 102:616-22.

40 Chhabra D, Nosworthy NJ, Dos R. The N-terminal fragment of gelsolin inhibits the interaction of DNase I with isolated actin, but not with the cofilin-actin complex. Proteomics 2005:5:3131-6.

41 Ulmer JS, Herzka A, Toy KJ, et al. Engineering actin-resistant human DNase I for treatment of cystic fibrosis. Proc Natl Acad Sci USA 1996;93:8225-9.

42 Zahm JM, Debordeaux C, Maurer C, et al. Improved activity of an actinresistant DNase I variant on the cystic fibrosis airway secretions. Am J Respir Crit Care Med 2001;163:1 153-7.

43 Gilliland FD, Berhane KT, Li YF, et al. Dietary magnesium, potassium, sodium, and children's lung function. Am J Epidemiol 2002;155:125-31.

44 Blitz M, Blitz S, Hughes R, et al. Aerosolized magnesium sulfate for acute asthma: a systematic review. Chest 2005; 128:337-44.

45 Swain R, Kaplan MB. Magnesium for the next millennium. South Med J 1999;92:1040-7.

46 Levy J, Smith AL, Kenny MA, et al. Bioactivity of gentamicin in purulent sputum from patients with cystic fibrosis or bronchiectasis: comparison with activity in serum. J Infect Dis 1983;148:1069-76.

47 Halmerbaver G, Arri S, Schierl M, et al. The relationship of eosinophil granule proteins to ions in the sputum of patients with cystic fibrosis. Clin Exp Allergy 2000;30:1771-6

48 Kilbourn JP. Composition of sputum from patients with cystic fibrosis. Curr Microbiol 1984;11:19-22.

49 Tomkiewicz RP, App EM, Zayas JG, et al. Amiloride inhalation therapy in cystic fibrosis: influence on ion content, hydration, and rheology of sputum. Am Rev Respir Dis 1993;148:1002-7.

50 Filliat M, Galabert C, Chazalette JP, et al. Pseudomonas aeruginosa strains and variations of $\mathrm{Mg}^{2+}$ level in the sputum of patients suffering from different respiratory diseases. Eur J Pediatr 1981;137:129.

51 Goldberger E. A primer of water, electrolyte and acid-base syndromes. Philadelphia, PA: Henry Kimpton, 1970, 298-312, 359-65.

52 Atsmon J, Dolev E. Drug-induced hypomagnesaemia: scope and management. Drug Saf 2005;28:763-88.

53 Adams JP, Conway SP, Wilson C. Hypomagnesaemic tetany associated with repeated courses of intravenous tobramycin in a patient with cystic fibrosis. Respir Med 1998;92:602-4

54 Akbar A, Rees JHM, Nyamugunduru G, et al. Aminoglycoside-associated hypomagnesaemia in children with cystic fibrosis. Acta Paediatr $1999 ; 88: 783-5$. 